\title{
PEDAGOGICAL RETURN ON INTERACTIVE WHITEBOARD INVESTMENT: TEACHERS‘ BELIEFS
}

\author{
Anita Janković ${ }^{1}$, \\ Milica Spasić-Stojković², \\ Dragana Spasić ${ }^{1}$ \\ ${ }^{1}$ Faculty of Philosophy, \\ University of Priština, \\ Kosovska Mitrovica, Serbia \\ ${ }^{2}$ Business School of Applied Studies, \\ Blace, Serbia
}

\begin{abstract}
:
The blooming and diverse literature on implementation of interactive whiteboards in education, in general, praises their effectiveness in learning and teaching. Despite their deceivingly ordinary appearance, they are reported to facilitate the integration of multimedia in the classroom, boost learner activity, support development of the 21 st century literacies, and cater to different learning styles. However, the acquisition of the technology is disproportionate to the adequate training of the teachers on its use and schools' systematic plan on its integration.

Critical theory of learning technology lays its emphasis on contextualizing the technology and accounting for various factors of its integration, such as the inherent nature of the technology, teacher's affective and cognitive attitudes, and students' awareness of its benefits. This paper focuses on teachers pedagogical beliefs as the grass roots of any change in learning and teaching. Special attention is paid to resistant adopters as they need the most scaffolded and guided training.

Therefore, the aim of this paper is twofold. Primarily, it will present arguments advocating use of IWBs, collected from the reviewed studies. Secondly, it will map attitudes and beliefs of the teaching staff at the Faculty of Philosophy in Kosovska Mitrovica and Business School of Applied Studies in Blace regarding the use of interactive whiteboards in teaching.
\end{abstract}

\section{Keywords:}

interactive whiteboard, teacher's beliefs, interactivity, learning technology, teacher training.

\section{INTRODUCTION}

It has become an imperative to modernize and improve teaching on a tertiary level, especially foreign language teaching, having in mind that English language is studied both at the English departments, as well as other universities and departments. At the departments of the English language and literature, future teachers are mostly prepared for primary and secondary education. Through modernization of teaching methods, they are prepared to use ICT in their future work. At other departments, where language is acquired as English for Special Purposes (ESP), use of modern technologies and devices (interactive whiteboards, for example) improves lessons and may raise the capacity of students to use these 
devices in their future work. In both cases, it would be beneficial to train students to use the interactive whiteboards for presentations of their papers, etc.

In the field of teaching training, or applied linguistics in a broader sense, certain principles need to be met to enable excellent results in acquisition of knowledge, in this case, English language. The selection of approaches needs to be considered, starting from functional, through cognitive, holistic, and interactional to communicative. Selection of methods depends on the selection of the approach, the range of methods starting from the grammar translation method, through the natural method, the audio-lingual, oral or situational language teaching, to silent way, Suggestopedia, and total physical response.

Selection of techniques, from drills, through use of poetry and drama techniques, to e-learning, is also very important. E- learning is based on two different models - designing the virtual classrooms or independent work of students [25]. The term blended learning' was also introduced in teaching training and applied linguistics in 2007 [10]. Classes are taught face to face, but the process of learning is also facilitated by PCs, Internet, and learning software, along with the interactive whiteboard (IWB) [43].

With the recent acquisition of interactive whiteboards, the teaching staff at our institutions is faced with a new challenge and, for some, even an obstacle. What is the value of this new tool and what trials will our current teaching practice and our preparation time endure? These questions roam our heads as we stare at the whiteness of the new boards. Therefore, we set to explore literature on the topic to better equip ourselves, as well as to map the beliefs of our colleagues on the instructional and motivational effects the IWBs.

\section{Literature review}

The importance and use of the interactive whiteboards were reviewed and studied by numerous authors. According to Wood and Ashfield [36], the proximity and speed of education change in an unpredictable manner. Technology offers a chance to students to enjoy learning. With the increase of the amount of technology in each classroom, interactive whiteboards are becoming common tool in many countries.

IWB technology was initially developed for presentation in office settings and, in terms of educational settings, appears to have been used first in higher education [6], [22]. As earlier reviews have noted, much of the early literature has been descriptive. It details the introduction of the new technology and therefore reflects the enthusiasm of the initial innovator' and early adopter ${ }^{\prime}$ [17] or missioner ' [12] who had a vision of what the technology might achieve. It was, perhaps, indicative of the potential of this technology in classrooms.

This potential was based on a number of affordances of the technology [41]. A number of benefits were identified, such as that IWBs were well adapted to whole-class teaching [10], particularly in terms of developing more effective demonstrations [6], presenting a variety of representations and aspects of display more generally. IWBs were identified as making it easier to incorporate and use a range of multimedia resources in lessons such as written text, pictures, video, sound, diagrams, websites [9], [27]. The resources created and presented are attractive to both teachers and students [4], [40], and they capture and hold students' attention much more strongly than other classroom resources [20]. One of the most widely claimed advantages of IWBs was that they were seen to motivate pupils, with resulting improvement in attention and behavior [47]. IWBs were perceived as linking with the fashion for different learning styles [4]. The interactive software available enabled teachers to model abstract ideas and concepts in new ways so that the pupils might respond to the activities and deepen their understanding [12], [23]. They could quicken the pace of lessons through the use of prepared materials which reduced the need to write on the board [4], [10], [12] and could smoothen lesson transitions [4]. The facility to save and then re-use materials which have been created or annotated could reinforce and extend learning over a sequence of lessons [40]. IWBs were considered to be relatively easy to use and therefore favored by teachers who otherwise struggled to incorporate technology into their classrooms [20].

Researchers have also studied teachers' pedagogical approaches to the use of IWBs in different domains, such as literacy [2], science [26], [38], [44], and mathematics [15]. The findings indicated that teachers developed various teaching strategies for integrating IWBs into their teaching to increase their interaction with students [15], to help explain complex concepts [32], and maintain students' attention [20], and to increase the opportunities for adapting other classroom materials [15]. Some researchers have also shown that teachers perceive reasons for not using IWBs as not having an IWB installed in each classroom [21], lack of time to design instructional lessons [39], lack of professional training and related teaching software, as well as difficulties in solving technological problems [21]. 
A number of studies on ICT tools used in education focus on understanding the development of teachers ICT skills, such as relationships between ICT skills, their pedagogical thinking and classroom practices [25], and integration of ICT in different academic subjects [36]. Sutherland et al. [36] also state the importance of choosing ICT tools to fit different classroom cultures, for which each technological tool needs to be selected within a particular socio-cultural setting and its functions need to be appropriately integrated into the subject content. Internet and web based learning systems are becoming essential to create interaction between teachers' teaching and students' learning [5], [46]. The IWB is one of the ICTs widely used in school settings to increase these interactions and develop teachers' pedagogical strategies by integrating the features of this particular device into teaching [39], [42].

The researchers further examined how the integration of IWB in teaching can enhance students' comprehension of mathematical thinking [43], motivation [16], [18], and performances [32]. Therefore, the use of IWBs has been evidenced to positively influence teachers' integrative skills, at the same time developing their pedagogical approaches and students' learning as associated outcomes.

Glover et al. [14] have shown that IWB encourages students' interest and increases students' concentration. Beeland's study [47] focused on verifying the effect of use of IWB as an educational material on active participation of students. Due to student engagement in lessons, teachers can maintain students' focus and interest and enhance classroom management [19].

With regards to language teaching, modern foreign language (MFL) teachers are also reported as using a range of materials on an IWB. Thomas [3] describes the use of CD- ROMs, websites, Word documents and PowerPoint slides in conjunction with the facility to highlight, annotate, drag, drop and conceal linguistic units: -You can create sequence linking sound files, web pages, images anything from your desktop and build it up, layer upon layer| [3]. The facility to mix visual and aural information is argued to facilitate the process of MFL learning, as learners can make connections between what they see and what they hear.

Although it can take time to prepare lessons with an IWB and to become technically accomplished [4], [11], [35], teachers report that planning time should eventually be reduced given the facility of IWB technology to save, share and re-use lesson materials [30]. Facing the class whilst teaching ICT is reported as a major advantage of IWB use, as it allows the teacher to spend more time focusing on the students [7], [20], [28], [37].
Regarding the drawbacks, it was noted that, at least initially, preparation for lessons took longer and it took time and experience to become technically accomplished [4], [13], [35]. Some researchers have highlighted that even when a teacher aims to use IWBs as a transformative pedagogic tool [24], lack of practical and methodological training can impede and frustrate such aims [8], [34]. Levy [35] observed that teachers who were already confident ICT users tended to become enthusiastic e early adopters' able to experiment and develop their own IWB use following initial training. Those teachers with less confidence and experience with ICT, however, were less able to be self-reliant, preferring instead more sustained and individual guidance as part of more structured continuing support, such as where more experienced users work alongside novices [10]. Several studies have also focused on teachers' attitudes about use of IWBs, and researchers have argued that some educators (both teachers and academicians) find it hard to be inspired by IWBs during their lessons [16], [20], [21]. Cost limitations are also a reason for educators not to include IWBs in the lessons, along with the lack of ICT competence and the need for teachers to prepare for IWB lessons [21].

A case study of Namli, Sahin, and Karatas [31] has shown that, like two sides of one coin, whiteboards also have disadvantages. IWB in a classroom will not guarantee results, as motivated teachers will motivate students. IWBs help teachers explain concepts in ways that capture students' attention, but the lessons require time to design and prepare. Unlike with the textbooks, teachers have to research, evaluate, interpret, install and maneuver software programs needed for IWB. Teachers who do not receive proper training on how to use IWBs often find them troublesome and complicated. As a result, teachers get frustrated and never use the full potential of IWBs.

\section{Study}

The study presented here was conducted in two HE institutions, Faculty of Philosophy in Kosovska Mitrovica and Applied Business School in Blace, which recently invested in acquiring and implementing interactive whiteboard technology. Both institutions attach great importance to innovation in teaching and learning, hence the investment in the educational technology. However, the introduction of IWBs was rather obscure in terms of training and scaffolding the teaching staff which inspired the authors to investigate the attitudes of the teachers towards the unfamiliar whiteboards now hanging in their classrooms. We were interested to map their: 
- general attitudes;

- perception of instructional effects of IWBs,

- perception of motivational effects of IWBs on the students;

- need for training.

The study was carried out with a quantative approach using a survey methodology followed by the descriptive method of data analysis. The instrument used in the survey was Hüseyin's questionnaire [33] which consisted of 25 statements, eight of which were negatively keyed. The online questionnaire was administered in Serbian and English, with the English version (Appendix 1) serving as the pilot to test the instrument validity with the English department at the Faculty of Philosophy, which led to slight revisions to the Serbian version of the questionnaire. The statements were rated on the five-point Likert scale which included a N/A option for the teachers who had no experience in using IWBs.

The survey included 68 teachers in both schools and since the participation was voluntary, a total of 50 teachers completed the questionnaire, yielding a $73 \%$ response rate. The data was collected and quantatively analyzed using Google Forms, online software. For the concise and economic presentation of the results, the graded scores on both sides of the scale were summed.

\section{Presentation and discussion of the results}

The broader framework of this study is the critical theory of learning technology [1] which lays its emphasis on contextualizing the technology and accounting for various factors of its integration, such as inherent nature of the technology, teacher's affective and cognitive attitudes, and students' awareness of its benefits. Sutherland et al. [36] quotes Schuck who named these factors -contextual factors| which play a major role in the successful implementation of the digital technology in education. In addition, Schuck identified other factors such as school culture, teacher training, time to practice and prepare materials, teacher confidence, and technical support. Other contextual factors to consider involve classroom setup and the quality of the equipment [39].

This study focuses on teachers' pedagogical beliefs as the grass roots of any change in learning and teaching, especially on those of resistant adopters as they need the most scaffolded and guided training. The survey shows that $17 \%$ of the participants never used the IWB in their classes, half of whom perceive themselves as -not the technological type|, while three participants expressed extremely negative attitude towards it. Among the other
$83 \%$ who used the IWB at least once, 4 people reported feeling embarrassed in front of it. Greiffenhagen [8] and Malavet [34] report that even the enthusiastic teachers suffer from the frustration and embarrassment when implementing IWB technology. Previous studies, including [15] and [21], agree that building IWB culture and providing ample professional development increases teachers' confidence and participation.

Figure 1 presents other answers in the category General attitudes. It paints a positive picture of the teaching staff who are primarily flexible and open to innovation $(66 \%)$ with positive attitude towards IWBs $(81 \%)$, and are aware of the need to change the teaching methodology with the use of the new teaching tools (82\%). Their responses also indicate a positive perception of the students abilities to handle new technology and face the challenges (83\%). The culture of innovation and teachers' beliefs are not unlike what Glover and Miller [11] report of the UK education. In addition, Hakkarainen [25] reported that teachers with experience in implementing learning technology emphasized its importance in the learning and teaching process more readily than resistant adopters, as was evident in our study. On the other hand, Smith et al. [20], in their review of literature, found evidence that the IWBs are preferred even by those who grapple with educational technology.

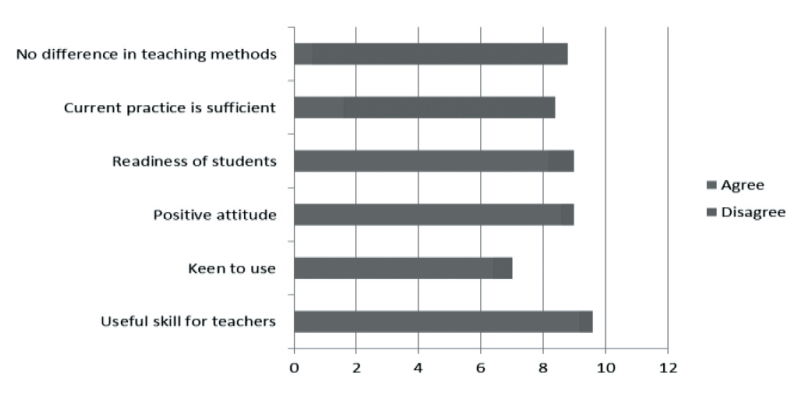

Fig. 1. General attitudes

The statements in the second category aimed at examining teachers' perceptions of the instructional effects of IWBs (Figure 2). The responses align with the results of the reviewed studies in the first section of the paper. First of all, the presentational value of the technology, as introduced in the literature review, was recognized by the survey participants.

IWBs provide opportunities for easier display of various materials (86\%) including multimedia in concordance with the findings of Johnson [9] and Ekhaml [27]. Explanation $(62 \%)$, revision $(76 \%)$ and saving of the material and notes generated during the lesson (76\%) were pointed 
out as main advantages of the tool. Kennewell [40] also documents these features as important and beneficial to the teachers he surveyed.

As much as $74 \%$ of the respondents believe that IWB increases the interactivity in class. Higgings et al. [20] and Kennewell et al. [42] found evidence which corresponds to our findings. However, only $48 \%$ of the respondents believe that the IWBs are useful for controlling the flow of the lesson with greater ease, though Glover and Miller [10] emphasize this feature in their report on new technologies. The results also show that that the teachers were well aware of the reduced time they would spend writing on the board (68\%) as well as the increased time of preparation it requires (52\%).

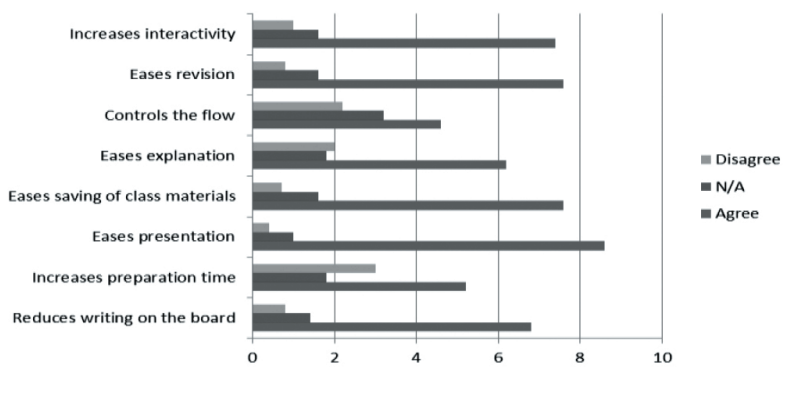

Fig. 2. Instructional effects

Statements probing teachers' beliefs on motivational effects on the students brought more diverse and less convincing results (Figure 3). The most prominent score indicates that IWBs are believed to make learning more interesting and fun (88\%). Miller et al. [15] pointed out that diverse teaching strategies combined with the IWB technology could captivate and inspire students. On the other hand, the survey participants are not as convinced in the increased motivation (70\%), activity (62\%) and attention of the students (68\%). Contrary to our findings, Beeland [47] gives priority to increased motivation and improved behavior of the students as a result of introducing IWBs in teaching. Similar studies, such as [14] and [19], also report increased interest and concentration.

Finally, responses to the statements in the last category show unanimous need for systematic training (94\%). In addition, $66 \%$ of the participants expressed unease and possible feeling of embarrassment if they had to use the IWBs without sufficient training. The others have identified themselves as digitally confident enough to learn through trial and error. Other studies reviewed in this paper confirm our findings. The data is largely in line with the findings of several other studies [2], [4], [13], [19], [31].

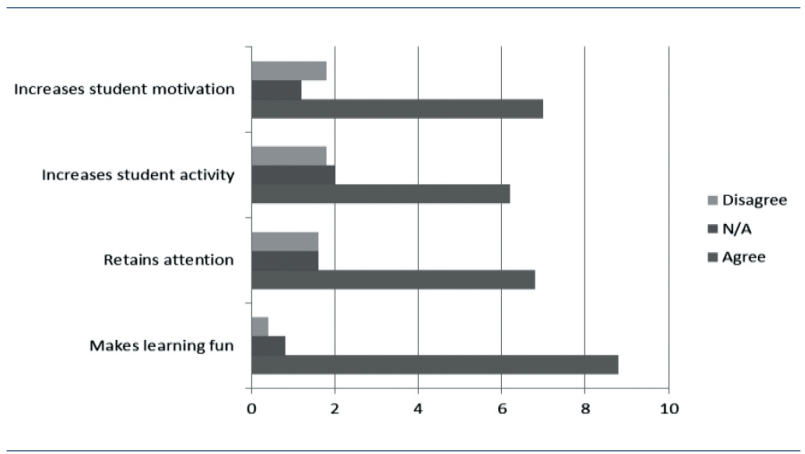

Fig. 3. Motivational effects

Furthermore, Johnson [19] contends that teachers also need courses on transformation of their pedagogy in order to effectively employ the full potential of IWBs. He also warns that a single training session with the representative of the IWB software company is insufficient and ineffective, while acknowledging that schools do not have the time nor the funds to provide regular training and monitoring sessions.

The main limitation of the survey is that the respondents and their answers were treated unilaterally because their profiles were not taken into consideration, such as age, work experience, digital skills or previous experience with learning technology, and even gender. The analysis does not enable us to determine the correlation of these personal aspects with the respondents' affective attitudes to get a larger picture, hence the results are static.

\section{Conclusion and recommendation}

The objective of this paper was to map the affective attitudes of the teaching staff at the Faculty of Philosophy in Kosovska Mitrovica and the Business School of Applied Studies in Blace with regards to the implementation of interactive whiteboards in their teaching. In addition, the paper presented a review of research literature on the topic in order to find validation for the results of our study. The relevance of the study is reflected in the recent acquisition of the IWB technology which is offered to the teachers without a systematic approach to their training.

The study was realized through an online questionnaire administered to 68 teachers from both institutions with 50 responses and overall response rate of $73 \%$. The statements were divided into 4 categories - general attitudes, instructional effects, motivational effects, and the need for training - and labeled on a five point Likert scale. The obtained data was, in general, aligned with the findings of the reviewed studies. Most respondents have a positive attitude toward the IWBs and recognize their instructional value. However, the perceived potential 
for increased motivation and participation of students was lower than expected or otherwise reported in the reviewed studies.

In conclusion, the results of the survey indicate a positive environment for successful integration of IWB technology with a strong emphasis on scaffolding and professional development opportunities. To fully exploit many potential affordances of the IWBs, the training program would have to be continuous, repetitive, comprehensive in terms of providing technical and pedagogical support, and multi-modal including peer training and monitoring. In addition, an institution-wide IWB culture should be nurtured and supported from the top, so that the grass roots can innovate and advance their teaching practice for the benefit of learning.

\section{REFERENCES}

[1] A. Feenberg, Critical theory of technology. Oxford University Press New York, 1991.

[2] A. Shenton and L. Pagett, -From bored'to screen: the use of the interactive whiteboard for literacy in six primary classrooms in England,| Literacy, vol. 41, no. 3, pp. 129-136, 2007.

[3] A. Thomas, -Little touches that spell success,| Times Educational Supplement, vol. 23, pp. 56-67, 2003.

[4] B. Ball, -Teaching and learning mathematics with an interactive whiteboard., | Micromath, vol. 19, no. 1, pp. 4-7, 2003.

[5] C. Chou, -Interactivity and interactive functions in web-based learning systems: a technical framework for designers,| British Journal of Educational Technology, vol. 34, no. 3, pp. 265-279, 2003.

[6] C. D. Stephens, -Forget the sailboard-let's go whiteboarding!,| Dental update, vol. 27, no. 5, pp. 236240,2000

[7] C. Drage, -Interactive all the way,| Times Educational Supplement, vol. 13, 2002.

[8] C. Greiffenhagen, -Interactive whiteboards in mathematics education, Paper to ICME, vol. 9, 2000.

[9] C. Johnson, -The writing's on the board,|Educational Computing \& Technology, vol. 9, pp. 58-59, 2002.

[10] D. Glover and D. Miller, -A report to Blackburn and Colne EAZ on New Technologies,| Keele, Department of Education, Keele University, 2001.

[11] D. Glover and D. Miller, -Missioners, tentatives and luddites: leadership challenges for school and classroom posed by the introduction of interactive whiteboards into schools in the UK,| in Part of the Symposium: New Technologies and Educational Leadership at the British Educational Management and Administration Society Conference, Newport Pagnell, UK, vol. 18, 2008.

[12] D. Glover and D. Miller, -Players in the management of change: Introducing interactive whiteboards into schools,| Management in Education, vol. 17, no. 1, pp. 20-23, 2003.

[13] D. Glover and D. Miller, -Running with technology: the pedagogic impact of the large-scale introduction of interactive whiteboards in one secondary school,| Journal of information technology for teacher education, vol. 10, no. 3, pp. 257-278, 2001.

[14] D. Glover, D. Miller, D. Averis, and V. Door, -The evolution of an effective pedagogy for teachers using the interactive whiteboard in mathematics and modern languages: An empirical analysis from the secondary sector,| Learning, Media and Technology, vol. 32, no. 1, pp. 5-20, 2007.

[15] D. Miller, D. Glover, and D. Averis, -Developing pedagogic skills for the use of the interactive whiteboard in mathematics,| British Educational Research Association, 2005.

[16] E. C. Schmid, -Potential pedagogical benefits and drawbacks of multimedia use in the English language classroom equipped with interactive whiteboard technology,| Computers \& Education, vol. 51, no. 4, pp. 1553-1568, 2008.

[17] E. M. Rogers, Diffusion of innovations. Simon and Schuster, 2010.

[18] G. Beauchamp and J. Parkinson, -Beyond the wow'factor: developing interactivity with the interactive whiteboard,| School Science Review, vol. 86, no. 316, pp. 97-103, 2005.

[19] G. L. Morgan, Improving student engagement: Use of the interactive whiteboard as an instructional tool to improve engagement and behavior in the junior high school classroom. ProQuest, 2008.

[20] H. J. Smith, S. Higgins, K. Wall, and J. Miller, Interactive whiteboards: boon or bandwagon? A critical review of the literature,| Journal of Computer Assisted Learning, vol. 21, no. 2, pp. 91-101, 2005.

[21] H. Slay, I. Siebörger, and C. HodgkinsonWilliams, -Interactive whiteboards: Real beauty or just lipstick'?,| Computers \& Education, vol. 51, no. 3, pp. 1321-1341, 2008.

[22] J. F. Murphy et al., -Use of an Interactive Electronic Whiteboard to Teach Clinical Cardiology Decision Analysis to Medical Students,| Journal of the American College of Cardiology, vol. 25, no. 2, p. 238- 247, 1995.

[23] J.-A. Edwards, M. Hartnell, and R. Martin, -Interactive whiteboards: Some lessons from the classroom,| 2002. 
[24] K. Burden, -Learning from the bottom up: The contribution of school based practice and research in the effective use of interactive whiteboards for the FE/HE sector. Learning and Skills Research-Making an Impact Regionally Conference,| The Earth Centre, Doncaster, vol. 21, 2002.

[25] K. Hakkarainen, H. Muukkonen, L. Lipponen, L. Ilomäki, M. Rahikainen, and E. Lehtinen, -Teachers ' information and communication technology (ICT) skills and practices of using ICT and their pedagogical thinking,| Journal of Technology and Teacher Education, vol. 9, no. 2, pp. 181197, 2001.

[26] K. Murcia and R. Sheffield, -Talking about science in interactive whiteboard classrooms, $\mid$ Australasian Journal of Educational Technology, vol. 26, no. 4, 2010.

[27] L. Ekhaml, -The power of interactive whiteboards.,| School Library Media Activities Monthly, vol. 18, no. 8, pp. 35-37, 2002.

[28] M. A. Bell, Update to survey of use of interactive electronic whiteboard in instruction. 2003.

[29] M. A. Bell, Why use an interactive whiteboard? A baker's dozen reasons. 2002.

[30] M. Lee and M. Boyle, -The educational effects and implications of the interactive whiteboard strategy of Richardson Primary School,| A Brief Review, 2003.

[31] N. A. Namli, M. C. Şahin, and T. Karataş, -A case study with academicians about using an interactive whiteboard in classroom,| Education Sciences, vol. 11, no. 1, pp. 23-35, 2016.

[32] O. S. López, -The digital learning classroom: Improving English language learners' academic success in mathematics and reading using interactive whiteboard technology,| Computers \& Education, vol. 54, no. 4, pp. 901-915, 2010.

[33] Ö. Z. Hüseyin, -Teachers` and students' perceptions of interactive whiteboards in the English as a foreign language classroom,| TOJET: The Turkish Online Journal of Educational Technology, vol. 13, no. 3, 2014.

[34] P. A. Malavet, -Interactive Whiteboards: The technology of the future, working with traditional pedagogical methodology,| Gainesville: College of Law. 1998.

[35] P. Levy, -Interactive whiteboards in learning and teaching in two Sheffield schools: a developmental study|, Sheffield Excellence in Cities Partnership, 2002.

[36] R. Sutherland et al., -Transforming teaching and learning: embedding ICT into everyday classroom practices, | Journal of Computer Assisted Learning, vol. 20, no. 6, pp. 413-425, 2004.
[37] R. Wood and J. Ashfield, -The use of the interactive whiteboard for creative teaching and learning in literacy and mathematics: a case study,| British journal of educational technology, vol. 39, no. 1, pp. 84- 96, 2008.

[38] S. Hennessy, R. Deaney, K. Ruthven, and M. Winterbottom, -Pedagogical strategies for using the interactive whiteboard to foster learner participation in school science,| Learning, Media and Technology, vol. 32, no. 3, pp. 283-301, 2007.

[39] S. Higgins, G. Beauchamp, and D. Miller, -Reviewing the literature on interactive whiteboards,| Learning, Media and Technology, vol. 32, no. 3, pp. 213-225, 2007.

[40] S. Kennewell, -Researching the influence of interactive presentation tools on teachers' pedagogy," 2006.

[41] S. Kennewell, -Using affordances and constraints to evaluate the use of information and communications technology in teaching and learning,| Journal of Information Techology for Teacher Education, vol. 10, no. 1-2, pp. 101-116, 2001.

[42] S. Kennewell, H. Tanner, S. Jones, and G. Beauchamp, -Analysing the use of interactive technology to implement interactive teaching,| Journal of Computer Assisted Learning, vol. 24, no. 1, pp. 61-73, 2008.

[43] S. Merrett and J.-A. Edwards, -Enhancing mathematical thinking with an interactive whiteboard,|Micromath, vol. 21, no. 3, pp. 9-12, 2005.

[44] S.-J. Jang and M.-F. Tsai, -Exploring the TPACK of Taiwanese elementary mathematics and science teachers with respect to use of interactive whiteboards,| Computers \& Education, vol. 59, no. 2, pp. 327-338, 2012.

[45] S.-J. Jang and M.-F. Tsai, -Reasons for using or not using interactive whiteboards: Perspectives of Taiwanese elementary mathematics and science teachers, | Australasian Journal of Educational Technology, vol. 28, no. 8, 2012.

[46] S.-J. Jang, -Exploration of secondary students' creativity by integrating web-based technology into an innovative science curriculum,| Computers \& Education, vol. 52, no. 1, pp. 247-255, 2009.

[47] W. D. Beeland, -Student engagement, visual learning and technology: Can interactive whiteboards help, in Annual Conference of the Association of Information Technology for Teaching Education, 2002. 


\section{APPENDIX 1 - QUESTIONNAIRE}

\section{General attitudes}

1. I like using IWB technology in my lessons.

2. I feel uncomfortable using IWBs in front of my students.

3. I have positive attitudes toward the use of IWBs in teaching.

4. I have negative attitudes toward the use of IWBs in teaching.

5. I do not think my students are ready for this technology.

6. What I do in class with traditional methods is sufficient for teaching.

7. I am not the type to do well with IWB-based applications.

8. There is no difference between my use of a traditional board and an IWB in terms of teaching techniques and methods.

\section{Instructional effects of IWBs}

9. Using the IWB resources reduces the time I spend writing on the board.

10. When using IWBs in the classroom, I spend more time for the preparation of the lesson.

11. Using IWBs makes it easier to reach different sources and display them to the whole class immediately.

12. IWBs are beneficial for saving and printing the materials generate during the lesson.

13. I can give explanations more effectively with the use of IWBs.

14. With the help of using the IWB, I can easily control the whole class.

15. I think IWBs can be a good supplement to support teaching.

16. Using IWBs makes me a more efficient teacher.

17. Using IWBs makes it easier for a teacher to review, reexplain, and summarize the subject.

18. I believe IWB is a useful technology for teachers to learn.

19. Using IWB makes the lessons more interactive.

\section{Motivational effects of IWBs}

20. I think IWBs make learning more enjoyable and more interesting.

21. I can keep my students' attention longer with the help of IWB technology.

22. I think IWBs increase the interaction and participation of the students.

23. I think my students are more motivated when I use an IWB in my lessons.

\section{Need for training}

24. I believe that training is required to teach with IWB technology.

25. If I do not get sufficient training, I do not feel comfortable with using IWBs in the classroom. 